\title{
MEDIAÇÃO PEDAGÓGICA NO CONTEXTO DO CURSO DE LETRAMENTO ESTATÍSTICO EM EAD
}

\author{
Maria Elisabette Brisola Brito Prado ${ }^{1}$ \\ Angélica da Fontoura Garcia Silva ${ }^{2}$ \\ Fátima Aparecida da Silva Dias ${ }^{3}$ \\ Michel da Costa ${ }^{4}$
}

\section{RESUMO}

Este artigo expõe uma investigação realizada em um curso de formação continuada sobre a temática Letramento Estatístico desenvolvido na modalidade a distância. O tema "Letramento Estatístico" se constitui cada vez mais uma demanda social, independentemente da área de formação e de atuação das pessoas. Estudiosos como Freire (1994), Gal (2005), Skovsmose (2008) e D’Ambrósio (2014) enfatizam a necessidade de formar cidadãos capazes de ler criticamente o mundo. Desse modo, a formação supracitada foi destinada aos profissionais de uma instituição de ensino superior privada que atuam na tutoria online de diferentes cursos de graduação. Este estudo teve por objetivo compreender as estratégias de intervenção de dois mediadores a partir das resoluções de uma situação de aprendizagem elaboradas pelos grupos de cursistas de uma das turmas. A metodologia, de caráter qualitativo, utilizou as respostas dos grupos disponíveis no Ambiente Virtual de Aprendizagem (AVA) do curso. Diante das soluções apresentadas, os dois mediadores relataram suas estratégias de intervenção, as quais foram descritas e analisadas à luz das teorias sobre a mediação e o ensino de representações gráficas. Por fim, esta investigação revelou que as estratégias em comum utilizadas pelos dois mediadores focaram em inserir os cursistas em uma postura ativa e reflexiva no processo de aprendizagem. Ressalta-se a importância de estratégias mediadoras voltadas à problematização, novos desafios e questionamentos que instiguem o cursista a conjecturar sobre suas ideias e a explicitar seu pensamento, favorecendo o desenvolvimento da autonomia para aprender no contexto da Educação a Distância (EaD).

Palavras-chave: Formação Continuada. Letramento Estatístico. Estratégias Mediadoras.

\footnotetext{
${ }^{1}$ Doutorado em Educação pela Pontifícia Universidade Católica de São Paulo. E-mail: bette.prado@gmail.com 2 Doutorado em Educação Matemática pelo Pontifícia Universidade Católica de São Paulo. E-mail: angelica. fontoura@gmail.com

${ }^{3}$ Doutorado e Mestre em Educação Matemática pela Universidade Bandeirante e Anhanguera. E-mail: fatima.a.dias@educadores.net.br

${ }^{4}$ Doutorado em Educação Matemática pela Universidade Anhanguera de São Paulo. E-mail: michel.costa@ unimes.br
} 


\title{
PEDAGOGICAL MEDIATION IN THE CONTEXT OF A DISTANCE LEARNING STATISTICAL LITERACY COURSE
}

\begin{abstract}
This article presents an investigation carried out in a continuing education course on Statistical Literacy, developed in Distance Learning modality. The topic of Statistical Literacy is increasingly becoming a social demand, regardless of people's area of training and practice. Scholars such as Freire (1994), Gal (2005), Skovsmose (2008), and D’Ambrósio (2014) emphasize the need to train citizens capable of critically reading the world. This training targeted professionals of a private higher education institution who work in online tutoring of different undergraduate courses. This study aimed to understand the intervention strategies of two mediators based on the resolutions of a learning situation developed by groups of students in one of the classes. The qualitative methodology used the group's answers available at the Virtual Learning Environment (VLE) of the course. Due to the resolutions presented, the two mediators reported their intervention strategies, which were described and analyzed by the current theories on mediation and teaching of graphical representations. Finally, this investigation revealed that the common strategies used by the two mediators focused on placing the students in an active and reflective posture in the learning process. It is worth noting the importance of mediating strategies focused on problematization, new challenges, and questioning that instigate students to reflect on their ideas and to explain their line of thought, favoring the development of autonomy to learn in the context of Distance Learning (DL).
\end{abstract}

Keywords: Continuing Education. Statistical Literacy. Mediating Strategies.

\section{MEDIACIÓN PEDAGÓGICA EN EL CONTEXTO DEL CURSO DE ALFABETIZACIÓN ESTADÍSTICA EN LA EDUCACIÓN A DISTANCIA}

\section{RESUMEN}

Este artículo presenta una investigación realizada en un curso de educación continua sobre el tema de Alfabetización Estadística desarrollado en la modalidad a distancia. El tema de la Alfabetización Estadística se está convirtiendo cada vez más en una demanda social, independientemente del área de formación y desempeño de las personas. Académicos como Freire (1994), Gal (2005), Skovsmose (2008) y D’Ambrósio (2014) enfatizan la necesidad de formar ciudadanos capaces de leer críticamente el mundo. Esta formación estuvo dirigida a profesionales de una institución privada de educación superior que trabajan en tutorías online para diferentes cursos de pregrado. Este estudio tuvo como objetivo comprender las 
estrategias de intervención de dos mediadores a partir de las resoluciones de una Situación de Aprendizaje elaboradas por grupos de alumnos de una de las clases. La metodología, de carácter cualitativo, utilizó las respuestas de los grupos disponibles en el entorno virtual de aprendizaje del curso. A la vista de las resoluciones presentadas, los dos mediadores informaron sus estrategias de intervención, las cuales fueron descritas y analizadas a la luz de las teorías sobre la mediación y la enseñanza de representaciones gráficas. Finalmente, esta investigación reveló que las estrategias comunes utilizadas por los dos mediadores se enfocaron en colocar a los participantes del curso en una postura activa y reflexiva en el proceso de aprendizaje. Destaca la importancia de estrategias mediadoras orientadas a la problematización, nuevos retos y preguntas que animen al cursante a conjeturar sobre sus ideas y explicar sus pensamientos, favoreciendo el desarrollo de la autonomía para aprender en el contexto de la EaD.

Palabras clave: Educación continua. Alfabetización estadística. Estrategias mediadoras.

\section{INTRODUÇÃO}

Com o crescente número de cursos oferecidos na modalidade a distância, tornase cada vez mais desafiador entender os processos de ensino e de aprendizagem que ocorrem numa configuração sem a presença física do professor. Na Educação a Distância (EaD), o ato de ensinar se desenvolve por diferentes meios, seja pela teleaula, interativa ou não, ou pela webaula, constituída por textos, imagens, links e vídeos. Além desses meios, geralmente, os cursos EaD contam com a tutoria on-line e/ou presencial, a qual é realizada por profissionais que interagem e acompanham o processo de aprendizagem dos estudantes. Portanto, essa modalidade de ensino se configura pela presença ampliada e diversificada de mediadores pedagógicos.

De fato, a EaD se caracteriza como uma nova forma de organizar a ação docente. Essa mudança "interfere diretamente na natureza do trabalho do professor, o qual antes era uma entidade individual, e passa a ser uma identidade coletiva." (MILL et al., 2018, p. 74).

As ações desses mediadores demandam a atuação de profissionais preparados em diferentes áreas do conhecimento (web designer, programador, designer instrucional, roteirista, especialista em conteúdo, pedagogo, psicólogo, entre outros), ou seja, de uma equipe multidisciplinar. Eles possuem saberes distintos e abrangentes e precisam estar em constante diálogo, assumindo uma postura colaborativa na criação e no desenvolvimento dos cursos EaD.

Em se tratando especialmente do profissional que interage diretamente com os estudantes, o tutor on-line e/ou presencial, ressalta-se que sua prática requer um conjunto 
de saberes - tanto aqueles relacionados ao conteúdo específico abordado no curso como aqueles de caráter pedagógico - que envolve as especificidades dessa maneira de ensinar e aprender, a qual rompeu com os limites de tempo e espaço, assim como ampliou e diversificou os recursos didáticos e as formas de comunicação. Nesse sentido, alguns autores, por exemplo, Prado e Almeida (2009), enfatizam a importância da criação de estratégias de ensino compatíveis com as características da EaD, considerando, inclusive, a necessidade de conhecer de que modo os estudantes aprendem nesse contexto.

Essa modalidade de ensino demanda, entre os vários desafios, a formação e a atuação do tutor on-line e/ou presencial. Geralmente, esse profissional atende muitos alunos, em uma variedade de situações, principalmente, aquelas que envolvem esclarecimentos de dúvidas sobre questões acadêmicas, pedagógicas e tecnológicas. Há situações em que ele também tem a função de corrigir as atividades avaliativas e dar retorno aos estudantes, entre os quais, aqueles que são considerados simples, por exemplo, informar se atividade está correta ou não, ou, ainda, indicar que a atividade precisa ser refeita. O fato é que cada instituição organiza a atuação da tutoria, seja ela virtual ou presencial. No entanto, várias pesquisas como as de Prado (2006); Souza, Sartori e Roesler (2008); Mill (2012); Mattar (2012); Ferreira e Mourão (2020) - têm mostrado a importância da interação do tutor com os educandos pela mediação pedagógica, ou seja, da intervenção na construção do conhecimento do aluno.

Sob esse enfoque da mediação pedagógica desenvolvida com a intencionalidade de propiciar o aprendizado do estudante, esta investigação teve como objetivo compreender as estratégias de intervenção de dois mediadores. Para tanto, partiu-se das resoluções de uma situação de aprendizagem elaboradas pelos grupos de cursistas participantes da formação continuada.

\section{MEDIAÇÃO PEDAGÓGICA ON-LINE}

A mediação pedagógica refere-se à atitude comprometida do professor e/ou do tutor (como vem sendo denominado no contexto da EaD) com a aprendizagem do aluno. Por meio dela, são feitas intervenções de forma construtiva e incentivadora respeitando o potencial real de aprendizagem do aluno.

Percebe-se, portanto, que ela está relacionada ao comportamento do mediador como interlocutor, debatedor ou incentivador. O mediador é o profissional que desenvolve a ação com a intencionalidade de ser "uma ponte - não uma ponte estática, mas uma ponte rolante, que ativamente colabora para que o aprendiz chegue aos seus objetivos." (MASETTO, 2000, p. 144-145). 
$\mathrm{Na}$ EaD on-line, geralmente, a função do tutor tem sido bastante ampla; envolve ações como: correções das atividades virtuais e avaliativas, controle da frequência dos alunos, verificação do material e esclarecimento de dúvidas sobre prazos de entregas. No entanto, muitas vezes, o tutor centra sua atuação em tirar dúvidas e esclarecer questões relativas às informações gerais administrativas, tecnológicas, envolvendo, como exemplo, o próprio uso do Ambiente Virtual de Aprendizagem (AVA). Dessa forma, acaba restando pouco tempo para esse profissional dar a atenção necessária às situações de aprendizagem que demandam intervenções mais elaboradas, no sentido de compreender a dificuldade do estudante, bem como de desenvolver estratégias didáticas adequadas para seu aprendizado (MILL et al., 2018).

Quando se trata de interações com intencionalidade pedagógica, como dar o retorno (feedback) de uma atividade, de modo a intervir no processo de aprendizagem do estudante, a ação do tutor torna-se mais complexa de ser viabilizada. Essa ação de caráter mediador não é fácil, pois requer desse sujeito conhecimentos de naturezas diversas, isto é, saberes acerca dos conceitos tratados no curso e questões pedagógicas relativas ao ensino e à aprendizagem do alunado.

Considerando a importância da mediação pedagógica do tutor on-line, um grupo de pesquisadores, participantes de um programa de pós-graduação stricto sensu da área de ensino de uma universidade particular, elaborou e desenvolveu um projeto de pesquisa intitulado "Mediação em EaD: contexto de um curso de Letramento Estatístico", o qual envolvia a realização de um curso de formação continuada de tutores.

\section{FORMAÇÃO CONTINUADA DE TUTORES}

O curso sobre a temática "Letramento Estatístico" constitui-se o contexto de um processo formativo voltado para profissionais que atuam na tutoria on-line de cursos de graduação de diferentes áreas do conhecimento. Esse tema foi escolhido, na medida em que o letramento estatístico tem sido cada vez mais uma demanda social, independentemente da área de formação e de atuação das pessoas. Estudiosos como Freire (1994), Gal (2005), Skovsmose (2008) e D’Ambrósio (2014) enfatizam a necessidade de formar cidadãos capazes de ler criticamente o mundo.

O desenvolvimento do letramento estatístico é fundamental para que se possa tomar decisões de forma consciente em várias situações do cotidiano, a saber: fazer escolhas para adquirir algo, analisar os índices da inflação de um determinado período e avaliar informações expressas em gráficos. Em outras palavras, esse conhecimento envolve a realização de uma leitura crítica dos dados estatísticos e sua interpretação em uma determinada conjuntura, de modo a desenvolver argumentos explicativos para serem debatidos e compreendidos no âmbito econômico, educacional, político e social. 
Segundo Pietropaolo et al. (2017), o letramento estatístico refere-se à competência individual de coletar, organizar, representar, interpretar e analisar dados em uma variedade de contextos. Isso inclui raciocinar e utilizar conceitos, representações e índices estatísticos para descrever, explicar e predizer fenômenos. Dessarte, essa competência é indispensável a fim de que cidadãos construtivos, engajados e reflexivos façam julgamentos bem fundamentados e tomem as decisões necessárias.

Com base nessa perspectiva, o curso de formação continuada foi elaborado como parte de um projeto de pesquisa desenvolvido por uma equipe de pesquisadores do programa de pós-graduação stricto sensu de uma universidade privada, cujo objetivo foi propiciar aos participantes - no caso, tutores que atuavam em diversos cursos de graduação EaD — vivenciar, na condição de alunos, as situações de aprendizagem — tanto aquelas relacionadas ao conteúdo do tema como as que envolvem a prática da mediação pedagógica em $\mathrm{EaD}$ - e refletir sobre essas circunstâncias.

O referido curso foi realizado na modalidade semipresencial, com carga horária de 120 horas. Desse total, 96 horas foram a distância, no AVA Moodle, tendo como foco o conteúdo do letramento estatístico, e 24 horas foram presenciais na universidade, nas quais se abordou o conteúdo teórico e prático sobre a mediação pedagógica na EaD.

Participaram 300 cursistas, os quais foram distribuídos em 6 turmas no AVA. Cada uma tinha o acompanhamento pedagógico de dois mediadores com formação superior em diversas áreas do conhecimento, inclusive, com pós-graduação e experiências na tutoria on-line.

Diante do cenário do Curso de Letramento Estatístico, delimitou-se o escopo deste estudo em uma das turmas buscando identificar e analisar as estratégias de mediação desenvolvidas pelos mediadores e relativas a uma situação de aprendizagem envolvendo a leitura e a interpretação de um gráfico.

\section{PROCEDIMENTOS METODOLÓGICOS}

A metodologia utilizada neste estudo foi de caráter qualitativo, por meio da busca dos dados concernentes aos retornos (feedbacks) de dois mediadores de uma das turmas do Curso de Letramento Estatístico. Essa devolutiva foi referente a resoluções de uma situação de aprendizagem denominada "Os lápis", realizadas pelos grupos de cursistas.

Os dois mediadores, denominados MD1 e MD2, tinham formação em Licenciatura em Matemática, e os grupos de cursistas dessa turma, denominados GC1, GC2, GC3, GC4 e GC5, tinham formação superior em Pedagogia e atuavam como tutores on-line em diversos cursos de graduação na modalidade EaD. 
Os dados disponibilizados no AVA do curso foram analisados com base nos princípios teóricos voltados ao letramento estatístico e à mediação pedagógica. Assim, são apresentadas, na Figura 1, a situação de aprendizagem "Os lápis", proposta no curso, bem como as respectivas resoluções dos grupos.

Figura 1 - Situação de aprendizagem "Os lápis".

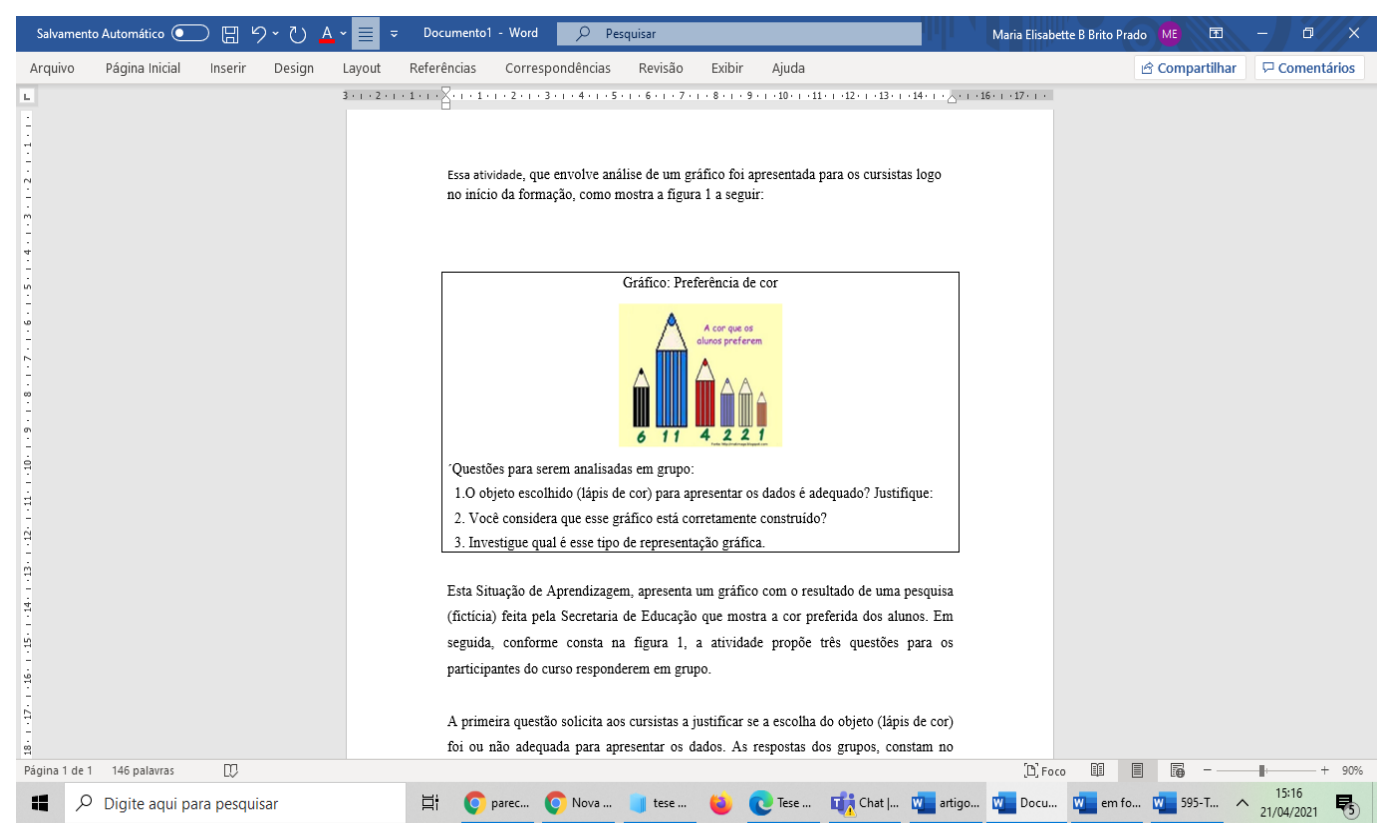

Fonte: Adaptada do Curso de Letramento Estatístico no AVA-Moodle

Essa situação de aprendizagem apresenta um gráfico, "Preferência de cor", com o resultado de uma pesquisa (fictícia) na qual é mostrada a cor preferida dos alunos. Em seguida, conforme consta na Figura 1, a atividade propõe três questões para que os participantes do curso respondam em grupo.

A primeira questão solicitou aos cursistas justificarem se a escolha do objeto (lápis de cor) foi ou não adequada para apresentar os dados. As respostas dos grupos constam no Quadro 1:

Quadro 1 - Respostas dos grupos de cursistas sobre a questão 1.

\begin{tabular}{|l|l|}
\hline Cursistas & \multicolumn{1}{c|}{ Respostas dadas pelos grupos de cursistas } \\
\hline GC1 & $\begin{array}{l}\text { "Sim. Pois o objeto (lápis de cor) faz parte do cotidiano dos(as) alunos(as) e traz } \\
\text { informações claras para o leitor. Porém, são necessárias perguntas, claras e } \\
\text { objetivas, para que a resposta do leitor não fique equivocada." }\end{array}$ \\
\hline GC2 & $\begin{array}{l}\text { "O objeto escolhido (lápis de cor) não é adequado para apresentar os dados, pois do } \\
\text { ponto de vista estatístico, para uma melhor análise, organização e interpretação de } \\
\text { dados, o mais adequado seria utilizar ferramentas descritivas, tipo gráficos e tabelas." }\end{array}$ \\
\hline
\end{tabular}




\begin{tabular}{|l|l|}
\hline GC3 & $\begin{array}{l}\text { "Sim, a escolha da figura foi adequada, pois foi construído a partir de figuras } \\
\text { representativas, facilitando a leitura universal do leitor, despertando a atenção do } \\
\text { público." }\end{array}$ \\
\hline GC4 & "Sim, ele apresentou clareza e objetividade." \\
\hline GC5 & "Sim, pois ele faz o levantamento de dados sobre a pesquisa coletada." \\
\hline
\end{tabular}

Fonte: Acervo da pesquisa (2019).

A segunda questão solicitou aos cursistas observarem e justificarem se esse tipo de gráfico representa corretamente o resultado da pesquisa. As respostas dos grupos constam no Quadro 2:

Quadro 2 - Respostas dos grupos de cursistas sobre a questão 2.

\begin{tabular}{|l|l|}
\hline Cursistas & \multicolumn{1}{c|}{ Respostas dadas pelos grupos de cursistas } \\
\hline GC1 & $\begin{array}{l}\text { "Parcialmente. Pois não se sabe ao certo o que o gráfico nos proporciona, pois ele } \\
\text { nos leva a mais de uma interpretação." }\end{array}$ \\
\hline GC2 & $\begin{array}{l}\text { "O gráfico apresentado não está corretamente construído, porque o ideal seria } \\
\text { utilizar uma ordem numérica, classificando do menor para o maior." }\end{array}$ \\
\hline GC3 & $\begin{array}{l}\text { "Não, pois verificamos que as imagens representadas no gráfico não estão de } \\
\text { acordo com a numeração descrita. Além disso, o gráfico poderia estar representado } \\
\text { de forma decrescente, facilitando a leitura." }\end{array}$ \\
\hline GC4 & "Não, pois as ordens dos números estão incorretas. Deveriam estar na posição crescente." \\
\hline GC5 & "Não, pois, no gráfico, as colunas 4 e 6 se encontram de forma invertidas." \\
\hline
\end{tabular}

Fonte: Acervo da pesquisa (2019)

A terceira questão pediu para que os cursistas investigassem o tipo de representação gráfica apresentada na situação de aprendizagem. As respostas dos grupos estão indicadas no Quadro 3:

Quadro 3 - Respostas dos grupos de cursistas sobre a questão 3.

\begin{tabular}{|l|l|}
\hline Cursistas & Respostas dadas pelos grupos de cursistas \\
\hline GC1 & "Pode ser um gráfico pictórico ou representado por colunas." \\
\hline GC2 & $\begin{array}{l}\text { "De acordo com a investigação realizada, neste cenário o tipo de representação } \\
\text { gráfica utilizada foi de coluna em que os dados são indicados na posição vertical, } \\
\text { indicando um dado quantitativo sobre diferentes variáveis e o gráfico de linha utilizado } \\
\text { para demonstrar uma sequência numérica." }\end{array}$ \\
\hline GC3 & $\begin{array}{l}\text { "É uma representação gráfica 'Pictograma',serve para traduzir conceitos } \\
\text { extremamente simplificada, facilitando a compreensão." }\end{array}$ \\
\hline GC4 & "Representação gráfica vertical." \\
\hline GC5 & "Gráfico de coluna vertical." \\
\hline
\end{tabular}

Fonte: Acervo da pesquisa (2019). 
Diante das respostas dos grupos, MD1 e MD2, individualmente, fizeram suas interpretações e manifestaram suas intervenções, as quais se constituem objetos de análise desta investigação.

\section{ANÁLISE E RESULTADOS}

Com relação à proposta da situação de aprendizagem "Os lápis", voltada à leitura e à interpretação de um gráfico, os dois mediadores, MD1 e MD2, salientaram que a escolha do objeto "lápis de cor" faz referência ao ambiente escolar. Por isso, consideraramna adequada para a representação em um pictograma que tem a intenção de chamar a atenção também pelas imagens relacionadas ao contexto. Os mediadores reconheceram que a questão 1 proposta na situação de aprendizagem tinha como finalidade incentivar os cursistas à reflexão no que tange ao uso desse tipo gráfico para representar a pesquisa, bem como conhecer seus argumentos.

A partir da interpretação das respostas dos grupos expressas no Quadro 1, MD1 e MD2 relataram suas estratégias de mediação pedagógica. Na sequência, expôs-se um resumo dos relatos de cada um dos mediadores:

Para o grupo GC2, o único que não considerou adequado o uso do gráfico pictórico, foram colocadas as seguintes questões: "O que é um pictograma? "Por que a figura [lápis de cor] da situação de aprendizagem da Figura 1 não representa um gráfico?" Para os grupos GC4 e GC5, a intervenção apresentada também ocorreu em forma de questionamentos, instigando os cursistas a repensarem sobre suas respostas. As questões propostas foram: "Foi o objeto escolhido [lápis de cor] que deu clareza e objetividade à apresentação dos dados? Se fossem colocados retângulos em vez de lápis, prejudicaria a leitura e/ou entendimento dos dados?" (Mediador 1)

"Para todos os cursistas foi solicitada a elaboração de um segundo gráfico, no formato de barras, com o uso do Excel, por exemplo. Essa seria uma forma de fazerem a comparação entre os dois gráficos - o ilustrado com os lápis de cor e o produzido no Excel. Em seguida, os cursistas foram instigados a refletirem e discutirem sobre a influência do instrumento pictórico na compreensão das informações apresentadas." (Mediador 2).

Analisando as estratégias de MD1 e MD2, percebeu-se que ambos procuraram problematizar as respostas apresentadas pelos cursistas. Ficou evidenciado que MD1 reconheceu que os cursistas do GC2 não identificaram o pictograma como gráfico, e que os do GC4 não deixaram claro o porquê de esse tipo de gráfico "apresentar clareza e objetividade". Diante disso, buscou provocar os cursistas dos grupos que demonstraram equívocos em suas respostas a repensarem sobre a questão proposta. O uso dessa estratégia mediadora, que é a de fazer perguntas, pode desencadear a reflexão dos cursistas sobre suas respostas, e essa ação Ihes favorece a assunção de uma postura ativa no processo de aprender. 
Quanto à estratégia de MD2, observou-se que ele não propôs intervenções diretas às dificuldades apontadas em cada uma das respostas, sugerindo aos grupos, independentemente das dificuldades demonstradas e das ideias equivocadas de alguns cursistas, a construção de um gráfico de barras com o uso do Excel para promover a comparação entre os gráficos. É interessante observar nessa estratégia de mediação que os cursistas foram instigados a elaborar um gráfico, produzir algo (um gráfico no Excel), para apoiar sua análise, fazendo a comparação entre a estrutura em barras e a pictórica. O que chama a atenção é que tal estratégia - uso da comparação - pode ser vista como uma ferramenta cognitiva — propicia a comparação —, que, segundo Piaget (1975), constitui um dos elementos que pode favorecer a construção de conhecimento.

As estratégias de mediação tanto de MD1 como de MD2 são voltadas à colocação dos cursistas em ação; entretanto, por si só, podem não ser suficientes. Por exemplo: as perguntas feitas por MD1 podem não ter um efeito apropriado para todos os cursistas do grupo, assim como a proposta feita por MD2, envolvendo a construção de um gráfico no Excel, pode ser algo muito complexo para alguns, uma vez que depende do nível real de cada cursista diante do escopo de conhecimento tratado no contexto da atividade proposta.

No sentido de completar essas estratégias mediadoras voltadas para a ação dos cursistas, destacou-se, conforme exposto por MD2, a importância de incluir a discussão entre os participantes sobre a questão de o registro pictórico ter influenciado "na compreensão das informações apresentadas no gráfico." Dar voz aos participantes, para que estes compartilhem suas ideias no grupo, pode ser uma proposta de ação que proporciona a reflexão sobre aquilo que estão aprendendo.

No tocante à questão 2 proposta na situação de aprendizagem, os cursistas foram levados a observar e a explicar se o gráfico "lápis de cor" estava construído corretamente. Diante das respostas dos grupos expressas no Quadro 2, MD1 e MD2 explicitaram suas estratégias de mediação, como segue:

\begin{abstract}
"Especificamente, o grupo GC1 foi instigado a explicitar as possíveis interpretações que podem ser feitas no gráfico apresentado (lápis de cor). E para todos os grupos foi apresentada indagações acerca da relação de proporcionalidade, ou seja, os cursistas foram questionados a observar se havia uma relação de proporcionalidade entre as figuras (lápis de cor) e os números que elas representam. Além disso, os grupos foram desafiados a mostrar a proporcionalidade ou a falta dela por meio de cálculos." (Mediador 1).

"De igual modo à questão anterior, os grupos foram instigados a elaborar um novo gráfico com o uso do Excel para a comparação dos dois gráficos, o da situação de aprendizagem e o do Excel, procurando identificar a existência de divergências entre eles. Também foi destacada para os cursistas a importância do conhecimento a respeito da maquiagem estatística, por meio de estudos." (Mediador 2).
\end{abstract}

Foi possível observar que MD1 e MD2 procuraram problematizar as respostas apresentadas. A solicitação de MD1 aos cursistas do grupo GC1 no que se refere à explicitação 
de quais as possíveis interpretações que poderiam ser feitas no gráfico pode favorecer a reflexão e a discussão sobre a importância de considerar os elementos constituintes de um gráfico (escala, unidade de medida). Ficou evidente, pela intervenção dada a todos os grupos, que a preocupação de MD1 foi de alertar para a existência ou não da relação de proporcionalidade, na medida em que, mesmo sem medir, é perceptível que as figuras não são proporcionais, tanto em seus comprimentos (alturas) e em suas larguras quanto em suas áreas.

No entanto, MD1 talvez não tenha notado que esse olhar para a existência da proporcionalidade ocorreu nos grupos GC3 e GC5, visto que eles reconheceram que as alturas e as larguras das imagens não eram proporcionais. É possível que isso se deva ao fato de nenhum deles ter expressado a ideia de proporcionalidade presente na situação. Notou-se que o GC3 fez menção à altura: "As imagens representadas no gráfico não estão de acordo com a numeração descrita". Já o GC5 notou a discrepância entre as medidas das alturas dos lápis ao expressar: "As colunas 4 e 6 se encontram de forma invertidas."

A estratégia mediadora de MD2 é a mesma feita na questão 1: solicitar aos cursistas que construam um novo gráfico para a comparação e o reconhecimento das divergências existentes. Ele aproveitou essa questão da situação de aprendizagem "Os lápis" para discutir sobre a Estatística, assim como favorecer a manipulação de informações - maquiagem estatística. Considerou-se, dessa maneira, que tal proposição é importante e desvela a significância do mediador em auxiliar o cursista a perceber a necessidade de fazer a leitura crítica dos dados representados no gráfico.

Vários pesquisadores, tais como: Freire (1994), Skovsmose (2008) e D’Ambrósio (2014), enfatizam a importância de desenvolver o pensamento crítico para a compreensão da realidade. Mais especificamente, em se tratando do letramento estatístico, Gal (2005) aponta para a necessidade de o indivíduo interpretar, compreender e avaliar criticamente as informações estatísticas para tomar decisões conscientes.

Nessa perspectiva, Pietropaolo et al. (2017, p. 344), analisando o diálogo estabelecido por um grupo de professores e um pesquisador, observam que: "a análise crítica da situação apresentada no cenário [situação] de aprendizagem", a qual envolvia manipulação na construção de gráficos, "não foi imediata para todos os seus integrantes." Segundo os autores, "a presença de um professor com conhecimento específico sobre o tema mais aprofundado [...] pareceu relevante, uma vez que ajudou a interpretar a informação estatística e elaborar a argumentação consistente". (PIETROPAOLO et al., 2017, p. 344).

A questão 3 proposta na situação de aprendizagem intencionou despertar nos cursistas o reconhecimento de um dos tipos existentes de representação gráfica apresentada na situação de aprendizagem "Os lápis". A partir das respostas dos grupos de cursistas expressas no Quadro 3, MD1 e MD2 explicitaram suas estratégias de mediação, conforme se vê no resumo de seus relatos: 
"Para todos os grupos foram feitos os seguintes questionamentos: "O que um gráfico de colunas precisa apresentar ao leitor? O que um gráfico pictórico precisa apresentar ao leitor?" (Mediador 1).

"Para todos os grupos foi retomada a tipologia de gráficos e foi solicitado que os cursistas estabelecessem comparações com o gráfico da situação de aprendizagem "lápis de cor". As dúvidas persistiram. Com isso, foi pedido para que os dados fornecidos pela questão fossem disponibilizados em todos os tipos de gráficos pesquisados, com o auxílio do Excel." (Mediador 2)

Relativamente, MD1 e MD2 mantiveram a estratégia de mediação adotada nas questões apresentadas anteriormente. MD1 questionou as características de um gráfico de colunas e de um pictórico com o propósito de levar os cursistas à reflexão acerca das aproximações e das diferenças entre os dois tipos. MD2 explicou para os cursistas as tipologias de gráficos com o intuito de auxiliá-los na comparação dos gráficos construídos por eles utilizando o Excel.

Ressaltou-se a relevância da utilização do Excel como um recurso didático que pode auxiliar a reflexão dos cursistas com relação à leitura de diferentes tipos de gráficos que podem ser produzidos. É importante compreender, a partir dos dados, a forma mais adequada de representá-los graficamente. Os documentos oficiais brasileiros, como a Base Nacional Comum Curricular (BNCC), por exemplo, consideram que as planilhas eletrônicas são recursos didáticos que "têm um papel essencial para a compreensão e utilização das noções matemáticas” (BRASIL, 2018, p. 276); esse mesmo documento, todavia, assevera que esses recursos "precisam estar integrados a situações que levem à reflexão e à sistematização, para que se inicie um processo de formalização", tal como a situação explorada pelo MD2.

Em vista disso, notou-se que a mediação pedagógica proposta tanto por MD1 como por MD2 revelou que ambos mantiveram atitudes compromissadas com a aprendizagem do cursista, haja vista que buscaram intervenções de forma construtiva e incentivadora, respeitando o potencial real de aprendizagem de seu alunado. Traços de "debatedor ou incentivador" foram observados nas respostas dadas por MD1 e MD2, segundo descreve Masetto (2000). Assim, verificou-se que os dois mediadores pautaram sua ação na intencionalidade de problematizar as situações e promover o espírito investigativo entre os participantes.

\section{CONSIDERAÇÕES FINAIS}

Este estudo apresentou algumas estratégias mediadoras realizadas por dois profissionais (MD1 e MD2) que atuaram no Curso de Letramento Estatístico. Para tanto, partiu da análise das respostas dadas pelos cursistas a uma situação de aprendizagem a qual envolveu a leitura e a interpretação de um gráfico. 
As estratégias utilizadas pelos dois mediadores focaram em propiciar aos cursistas a inserção de uma postura ativa e reflexiva no processo de aprender, enfatizando a qualidade do feedback da mediação na abordagem formativa. As intervenções se desenvolveram com base na problematização, em novos desafios e questionamentos que instigam o cursista a conjecturar suas ideias e a explicitar seu pensamento, o que permite desenvolver a autonomia para aprender no contexto da EaD.

Exploraram-se aqui algumas possibilidades que, para serem colocadas em prática, exigem do mediador o conhecimento do conteúdo que está sendo abordado (conceitos, diferentes formas de representação), neste caso em específico, o letramento estatístico. Elas também demandam ao tutor um saber relativo ao processo de aprendizagem do aluno, que envolve o reconhecimento dos significados que podem ser atribuídos pelo educando.

Essa prática mediadora no contexto da EaD torna-se mais complexa diante de outros elementos, até mesmo, de caráter tecnológico. Esses fatores precisam ser integrados para que a mediação pedagógica ocorra de forma efetiva nessa modalidade de ensino e aprendizagem.

\section{REFERÊNCIAS}

BRASIL. Ministério da Educação. Base Nacional Comum Curricular. Brasília: MEC, 2018.

D’AMBRÓSIO, U. Reflexões sobre conhecimento, currículo e ética. In: MACHADO, N. J.; D’AMBRÓSIO, U.; ARANTES, V. A. (org.). Ensino de Matemática: pontos e contrapontos. São Paulo: Summus, 2014, p. 73-122.

FERREIRA, D. M.; MOURÃO, L. Papel de professor tutor na percepção de discentes e dos próprios tutores. EaD em Foco. São Paulo, v. 10, n. 2, 2020.

FREIRE, P. A importância do ato de ler. São Paulo: Cortez, 1994.

GAL, I. Statistical literacy: meanings, components, responsibilities. In: BEN-ZVI, D.; GARFIELD, J. (ed.). The challenge of developing statistical literacy, reasoning and thinking. Netherlands: Kluwer, 2005. p. 3-15.

MASETTO, M. T. Mediação pedagógica e o uso da tecnologia. In: MORAN, J. M.; MASETTO, M. T.; BEHRENS, M. A. (org.) Novas Tecnologias e Mediação Pedagógica. São Paulo: Papirus, 2000. p. 141-171.

MATTAR, J. Tutoria e interação em educação a distância. São Paulo: Cengage Learning, 2012.

MILL, D. Docência Virtual: uma visão crítica. Campinas: Papirus, 2012. 
MILL, D.; SANTIAGO, G.; SANTOS, M.; PINO, D (org.). Educação a Distância: dimensões da pesquisa, da mediação e da formação. São Paulo: Artesanato Educacional, 2018.

PIAGET, J. Aprendizagem e conhecimento. Rio de Janeiro: Freitas Bastos, 1975.

PIETROPAOLO, R. C.; GARCIA SILVA, A. da F.; PRADO, M. E. B. B.; GALVÃO, M. E. E. L. Letramento Estatístico na Formação Continuada de Professores dos Anos Iniciais com Foco nas Representações Gráficas. Revista de Ensino, Educação e Ciências Humanas, Londrina, v. 18, n. 4, p. 341-346, 2017. Disponível em: https://revista. pgsskroton.com/index.php/ensino/article/view/5416. Acesso em: 10 jul. 2019.

PRADO, M. E. B. B. A Mediação Pedagógica: suas relações e interdependências. In: SIMPÓSIO BRASILEIRO DE INFORMÁTICA NA EDUCAÇÃO, 17., 2006, Brasília. Anais [...], Brasília: UNB/UCB, 2006. p. 101-110. Disponível em: http://www.br-ie.org/pub/index. php/sbie/article/view/470. Acesso em: 20 jun. 2019.

PRADO, M. E. B. B.; ALMEIDA, M. E. B. Formação de Educadores: Fundamentos reflexivos para o contexto da Educação a Distância. In: VALENTE, J. A.; BUSTAMANTE, S. B. V. (org.). Educação a Distância: prática e formação do profissional reflexivo. São Paulo: Avercamp, 2009. p.65-82.

SOUZA, A. R. B.; SARTORI, A. S.; ROESLER, J. Mediação Pedagógica na Educação a Distância: entre enunciados teóricos e práticas construídas. Rev. Diálogo Educ., Curitiba, v. 8, n. 24, p. 327-339, maio./ago. 2008.

SKOVSMOSE, O. Desafios da reflexão em educação matemática crítica. Campinas: Papirus, 2008.

Recebido em 05 de outubro de 2021 Aprovado em 23 de novembro de 2021 